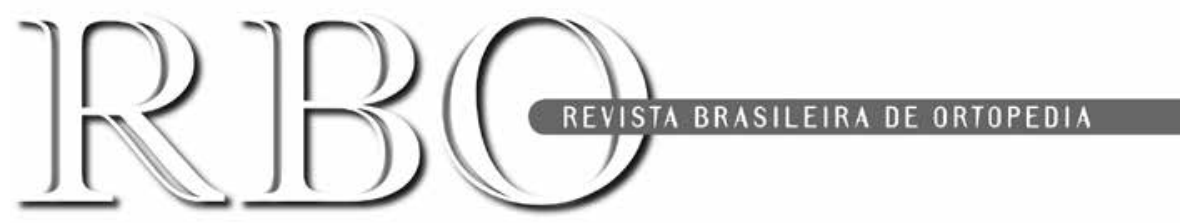

\title{
Editorial
}

\section{A hundred years of knee arthroscopy}

Looking into the cavities of the human body by means of devices, without having to make an incision in the skin, has always been the dream of surgeons. The quest to light up these dark spaces was resolved for the first time in 1886, with the advent of the first cystoscope fitted with an incandescent bulb, designed by Leiter and Nitze in Germany. In 1910, it was improved on by the Swedish physician Hans Christian Jacobaeus, with an incandescent light to examine the abdomen and thorax.

In the knee, long before we might imagine, more precisely in April 1912, at the $41^{\text {st }}$ Congress of the German Society of Surgeons, held in Berlin, which was attended by more than 1200 surgeons from Europe, Scandinavia and Russia, Severin Nordentoft, an unknown Danish surgeon, presented his invention: a 5-mm "trokart-endoscope", similar to that of Jacobaeus, but for use in the knee joint. In his enthusiastic text on the procedure in the knee, he described the term "arthroscopy" for the first time:

"Knee arthroscopy is very advantageous. We were afraid because the capacity of the joint is very small for us to try and perform a general examination. We learned that this problem does not exist, at least in the ventral (anterior) part of the joint, and that knee arthroscopy can actually be performed very well."

The results were published in two German periodicals, one of the congress itself, and the other of the Zentralblatt für Chirurgie, containing basically the same description, using a 90-degree optic with a thickness of $5 \mathrm{~mm}$. It is interesting to note that in these publications, Nordentoft used the term "arthroscopy", this being the first recorded report with the word, making him what can be considered the first arthroscopist.

Six years later, in 1918, Dr. Kenji Takagi, in Japan, gave his description of knee endoscopy. He performed diagnostic arthroscopies in knees with tuberculosis, but only published his case series in 1931, using a cystoscope of $3.5 \mathrm{~mm}$ in diameter, and reported, for the first time, the ease of distending the knee joint with a saline solution, making it easier to examine the joint.

On the other side of the world, after the First World War, the first to develop the pioneering technique in the knee described by the Danish Nordentoft was a Swiss surgeon called Eugin Bircher, at the Aarau General Hospital in the small town of Aarau, capital of the canton of Aargau, in Switzerland. Analyzing the reports of this Swiss surgeon, we see that he was the third to perform arthroscopy in the world, but the second to publish his reports, long before Takagi. In 1920, he published the report of his first one hundred arthroscopies for meniscectomies, with good results, earning him the title of "expert knee surgeon". Besides lesions of the meniscus, he reported that the second highest incidence was anterior cruciate ligament injury. In 1933, at the Congress of the German Society of Surgeons, in Berlin, he presented 832 menisectomies performed by arthroscopy.

Thanks to his contributions to the development of arthroscopy, Eugin Bircher and Kenji Takagi are considered by many surgeons to be the "fathers of arthroscopy".

The first American arthroscopist was Philip Heinrich Kreuscher, physician to the Chicago White Sox baseball team. Since 1919, he had taken a keen interest in the study of semilunar cartilages of the knee, and in 1925 he published the article: "Semilunar Cartilage Disease - A Plea for the Early Recognition by Means of the Arthroscope", becoming the pioneering American in knee arthroscopy. This article does not refer to the type of arthroscope used, but it was very similar to Jacobaeus' endoscope. Kreuscher performed various experiments to try and distend the knee, using nitrogen, oxygen and formaldehyde. He also used lipid in some cases, performing radiographies in the same procedure, and becoming the pioneer in knee arthrography.

In 1931, while working at the Hospital for Joint Diseases in New York, Dr. Michael Bruman began working with a 4-mm arthroscope that he and Reinhold Wappler had designed. The results were published in 1931, entitled: "Arthroscopy or the direct visualization of joints. An experimental cadaver study".

After the Second World War, Dr. Masaki Watanabe, at the University of Tokyo, was the great developer of arthroscope models, using the model created by his professor and mentor, Dr. Kenji Takagi. In 1957, he published the first atlas of arthroscopy, and in the following year, developed arthroscope number 21, which was the first to be produced globally, and the last to use incandescent light. In 1967, Watanabe presented arthroscope number 22, which was equipped with cold light, or fiber light. He was also the first to develop the concept of "triangulation" involving the use of materials by different portals.

In Brazil, arthroscopy was first performed at the beginning of the 1970s, with Jair Vieira Gomes of Rio de Janeiro and Luis Roberto Marczyck and Gilberto Camanho in São Paulo.

A fact that consolidated arthroscopy in Brazil was the visit of Masaki Watanabe to the Orthopedics Institute of the School of Medicine of the University of São Paulo (USP), and the visit of Yoshiki Okumura, of the Hospital do Servidor Público Estadual de São Paulo, to Dr. Watanabe in Tokyo; both visits took place at the beginning of the 1970s.

The first written work - therefore the first document - was that of Jair Vieira Gomes on "arthroscopy in the diagnosis of rheumatic diseases", published in 1972.

We therefore believe that the historical beginning of arthroscopy was in 1972 and that we can commemorate 40 years of arthroscopy in Brazil this year. We take advantage of this moment to give a brief history of Brazilian arthroscopy.

Even with so many studious surgeons of arthroscopy over the years, we cannot neglect to pay homage to the first to achieve this feat, and to publish a scientific paper on his accomplishment. Therefore, we congratulate Dr. Severin Nordendoft, as we celebrate 100 years since his accomplishment! 